Old Dominion University

ODU Digital Commons

OEAS Faculty Publications

Ocean, Earth \& Atmospheric Sciences

1987

\title{
Acceleration of Nutrient Uptake by Phytoplankton in a Coastal Upwelling Ecosystem: A Modeling Analysis
}

Richard C.Zimmerman

Old Dominion University, rzimmerm@odu.edu

James N. Kremer

Richard C. Dugdale

Follow this and additional works at: https://digitalcommons.odu.edu/oeas_fac_pubs

Part of the Environmental Monitoring Commons, Marine Biology Commons, and the Oceanography Commons

\section{Repository Citation}

Zimmerman, Richard C.; Kremer, James N.; and Dugdale, Richard C., "Acceleration of Nutrient Uptake by Phytoplankton in a Coastal Upwelling Ecosystem: A Modeling Analysis" (1987). OEAS Faculty Publications. 121.

https://digitalcommons.odu.edu/oeas_fac_pubs/121

\section{Original Publication Citation}

Zimmerman, R.C., Kremer, J.N., \& Dugdale, R.C. (1987). Acceleration of nutrient uptake by phytoplankton in a coastal upwelling ecosystem: A modeling analysis. Limnology and Oceanography, 32(2), 359-367. doi: 10.4319/lo.1987.32.2.0359

This Article is brought to you for free and open access by the Ocean, Earth \& Atmospheric Sciences at ODU Digital Commons. It has been accepted for inclusion in OEAS Faculty Publications by an authorized administrator of ODU Digital Commons. For more information, please contact

digitalcommons@odu.edu. 


\title{
Acceleration of nutrient uptake by phytoplankton in a coastal upwelling ecosystem: A modeling analysis ${ }^{1,2}$
}

\author{
Richard C. Zimmerman, ${ }^{3}$ James N. Kremer, and Richard C. Dugdale \\ Allan Hancock Foundation and Department of Biological Sciences, \\ University of Southern California, Los Angeles 90089-0371
}

\begin{abstract}
Studies of upwelling centers in the eastern Pacific suggest that maximum rates of nitrate uptake (light and nutrient saturated) increase, or shift-up, as newly upwelled water moves downstream. The rate of shift-up appears to be related to irradiance and the ambient concentration of limiting nutrient at the time of upwelling. A mathematical model was developed to evaluate effects of irradiance and initial nitrate concentration on temporal patterns of shift-up and subsequent time scales of nutrient utilization over a range of simulated upwelling conditions. When rates consistent with field studies were used, complete shift-up was possible only under certain conditions, and the time scale was on the order of 7-10 d. These results are consistent with field observations. Increased initial nitrate concentrations resulted in more rapid depletion of the nutrient supply. Making acceleration of $V_{\max }$ constant and independent of the nitrate concentration reversed the qualitative pattern of nutrient utilization and predicted longer time scales in the region of optimal growth (12$15 \mathrm{~d})$ than have been observed in the field. Since changes in nitrogen-specific $V_{\max }$ observed in situ may be due to downstream sinking of detrital nitrogen, a third hypothesis was evaluated, in which there was no shift-up in $V_{\max }$. This last scenario is untenable, predicting time scales of nutrient utilization two to three times longer than observed in the field.
\end{abstract}

New primary production in upwelling systems results from the introduction of cold, nutrient-rich water into the illuminated surface layer (Dugdale and Goering 1967). Phytoplankton cells brought to the surface during upwelling are in a relatively inactive state, and changes occur in response to light and nutrient availability as the phytoplankton moves offshore with the upwelled water. Biomass-specific nitrate uptake rates increase downstream (MacIsaac et al. 1974; Dugdale 1976; Wilkerson and Dugdale 1987), and increases in rates of carbon-related processes appear to lag changes in nitrate uptake (MacIsaac et al. 1985). Under certain conditions, upwelling systems can become highly productive, forming dense blooms (Barber and Smith 1981). However, not all upwelling systems or events are as efficient at converting dissolved inorganic nutrients into biomass, as productivity ultimately depends on the total

\footnotetext{
1 This research was supported by NSF grants OCE 82-15222 and OCE 85-05400 to the Organization of Persistent Upwelling Structures (OPUS) Program.

${ }^{2}$ Contribution 419 from the Allan Hancock Foundation, University of Southern California.

${ }^{3}$ Present address: Hopkins Marine Station, Pacific Grove, CA 93950.
}

amount of nutrients added and the mixing depth of the system during each event (Codispoti et al. 1982).

The transition from slow to fast growth in response to improved environmental conditions involves a complex series of biochemical steps, first described for Escherichia coli as shift-up (Schaechter 1968). The term shift-up has been extended to refer to increases in the biomass-specific nutrient uptake capacity of the phytoplankton as it responds to changes in the physical environment associated with downstream transport in the upwelling plume (Dugdale 1976; MacIsaac et al. 1974, 1985). Completion of this transition in $E$. coli requires 2-3 doublings and a time scale on the order of $4 \mathrm{~h}$. Slower doubling times characteristic of phytoplankton suggest that analogous processes occur at commensurately longer time scales. Shift-down can be induced by nutrient depletion, and the time required to return to a fully shifted-up state is related to the duration of nutrient depletion for short-term experiments (120 h or less: Collos 1980). However, studies of the effect of prolonged nutrient depletion and subsequent nutrient pulses of varying size on rates of shift-up have not been performed.

The existence in newly upwelled water of 
a period of increasing nitrate uptake has been shown for both Peru coastal waters $\left(15^{\circ} \mathrm{S}\right.$ : MacIsaac et al. 1985) and for Pt. Conception, California (Wilkerson and Dugdale 1987). Slopes of rate vs. time curves are variable and appear to be related to the concentration of limiting nutrient at the time of upwelling, as well as to the depth of the mixed layer.

Although the occurrence of this shift-up phenomenon has been demonstrated in upwelling systems, the general mechanisms underlying it are not well understood because measurements made on field samples always contain a mix of phytoplankton species as well as varying amounts of detrital material. High levels of detrital nitrogen in newly upwelled water (SooHoo 1985) may cause significant underestimation of N-normalized uptake rates in the early stages. Downstream sinking of detrital nitrogen and growth of the phytoplankton population could cause the pattern observed by Wilkerson and Dugdale (1987). Nevertheless, the pattern observed is clearly an inherent feature of at least some upwelling centers, and changes in specific nutrient uptake rates have important implications for the primary production process.

A numerical simulation model was developed both to investigate the ramifications of the primary hypothesis and to assess the credibility of two alternative hypotheses: the rate of shift-up is dependent on the concentration of limiting nutrient in newly upwelled water; the rate of shift-up is constant and independent of the initial nutrient concentration; and the shift-up phenomenon is an artifact and maximum uptake velocities are, in reality, constant. Our goal was to eliminate those hypotheses inconsistent with patterns and time scales observed during upwelling studies at several locations. We thank P. Bienfang, K. Brink, J. SooHoo, and F. Wilkerson for comments and suggestions.

\section{The model}

Figure 1 is a diagrammatic summary of the model. A fixed amount of nitrate, representative of upwelling source water, was available at the beginning of each simulation. At any given time, nitrogen-specific uptake of nitrate $\left(V_{N}\right)$ was limited by its ambient concentration $(N)$ according to the Monod equation:

$$
V_{N}=V_{\max } \frac{N}{K_{s}+N} .
$$

The value of the half-saturation constant $\left(K_{s}\right)$ does not appear to shift-up, as field observations show $<2$-fold change from highest to lowest values, in contrast to $V_{\max }$ which changes by two orders of magnitude (Wilkerson and Dugdale 1987). In tests of the three hypotheses, $K_{s}$ was held constant, but different formulations controlled the value of $V_{\max }$.

Hypothesis 1-According to the nutrientdependent hypothesis, $V_{\max }\left(\mathrm{h}^{-1}\right)$ increased toward its hypothetical maximum value at a rate controlled by the nitrate concentration at the beginning of each run. The initial value of $V_{\text {max }}$, normalized to particulate nitrogen, was set to $0.001 \mathrm{~h}^{-1}$, typical of minimum values at upwelling centers (MacIsaac et al. 1985; Wilkerson and Dugdale 1987). $V_{\max }$ was allowed to increase as much as two orders of magnitude during each run, to an empirical maximum value of $0.1 \mathrm{~h}^{-1}$. The effect of the initial nitrate concentration on the acceleration $\left(A, \mathrm{~h}^{-2}\right)$ of $V_{\max }$ was estimated by linear regression analysis of the OPUS field data (Fig. 2; Wilkerson and Dugdale 1987):

$$
A=\left(4 \times 10^{-5}\right) N+\left(4 \times 10^{-5}\right) .
$$

$V_{\max }$ increased each time step at this acceleration rate until it reached a value of 0.1 $\mathrm{h}^{-1}$ or until the nutrient supply was depleted. $N$ is the initial nitrate concentration $(\mu \mathrm{g}-$ atoms $\mathrm{N}$ liter ${ }^{-1}$ ) at the time of upwelling.

Light effect-The rate at which phytoplankton takes up nitrate is constrained by the amount of light available (MacIsaac and Dugdale 1972; MacIsaac et al. 1985). This effect was modeled to be proportional to the degree to which photosynthesis was light limited. Light availability was based on a $12: 12 \mathrm{~L} / \mathrm{D}$ cycle, with the instantaneous intensity at the surface $\left(I_{t}\right)$ determined by time of day during the 12 daylight hours:

$$
I_{t}=I_{\max } \times \sin \left(P i-\frac{T}{12}\right) .
$$

$I_{\max }$ was the maximum irradiance at noon 


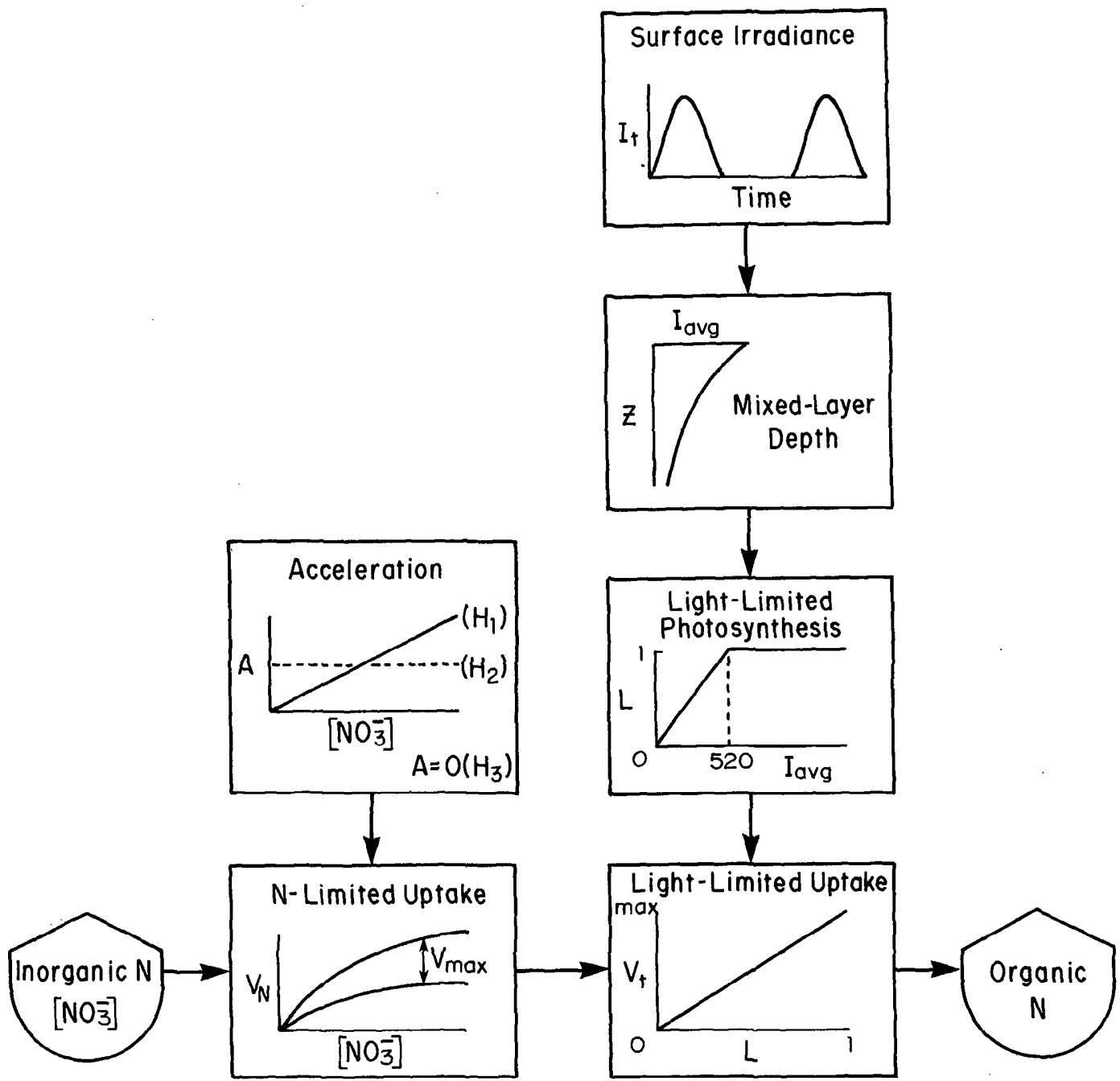

Fig. 1. A diagram of the shift-up model. The conversion of nitrate to organic nitrogen is controlled by nutrient and light availability. "Tank" symbols represent nitrogen storage compartments. Uptake follows the Monod equation, except the value of $V_{\max }$ can increase over time. Under hypothesis 1 , the rate of increase is regulated by the initial nitrate concentration (solid diagonal). Under hypothesis 2 (dashed line), the rate of acceleration is fixed for all initial nitrate concentrations. Under hypothesis 3 , there is no change in $V_{\max }$. Finally, conversion of nitrate to organic $\mathrm{N}$ is controlled by the degree to which photosynthesis is light limited.

where $T$ was the time (h). $I_{t}$ was 0 at night. Irradiance was averaged over the mixed layer:

$$
I_{\mathrm{avg}}=I_{t}\left[\frac{1-\exp (-k z)}{k z}\right]
$$

where $k$ was the coefficient of diffuse attenuation $\left(\mathrm{m}^{-1}\right)$, and $z$ was the depth of the mixed layer $(\mathrm{m})$. An average attenuation coefficient $\left(k=0.25 \mathrm{~m}^{-1}\right)$, calculated from
OPUS-83 field data, was used for all runs. Mixed-layer depths varied from 0 to $45 \mathrm{~m}$ in different trials, but remained constant for each run. The saturating light intensity for photosynthesis $\left(I_{k}\right)$ was estimated from OPUS-83 field data to be about $520 \mu$ Einst $\mathrm{m}^{-2} \mathrm{~s}^{-1}$ (Fig. 3). A coefficient of light limitation $(L)$ was calculated to range linearly from 0 to 1 as $I_{\text {avg }}$ went from 0 to $520 \mu$ Einst $\mathrm{m}^{-2} \mathrm{~s}^{-1}$, representing percent saturation of photosynthesis: 


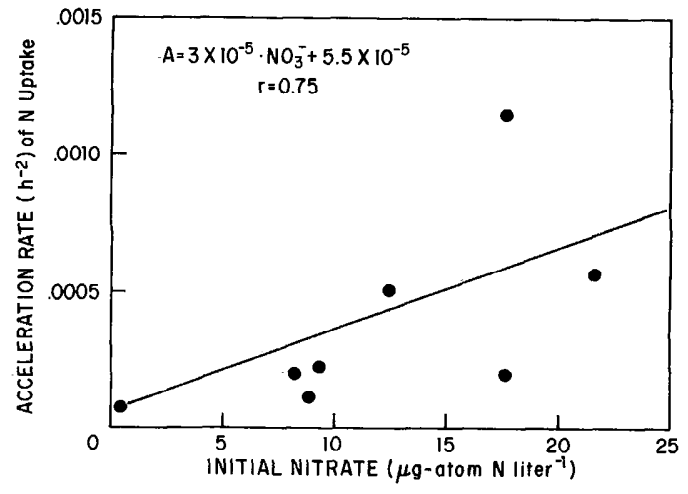

Fig. 2. Dependence of acceleration of $V_{\max }$ on initial nitrate concentration (from Wilkerson and Dugdale 1987 , omitting the shaded barrel). Least-squares regression: $A=\left(4 \times 10^{-5}\right) \mathrm{NO}_{3}^{-}+\left(4 \times 10^{-5}\right), r^{2}=$ 0.57 , regression ANOVA $F=6.53, P<0.05$.

$$
L=0.002 \times I_{\text {avg }} .
$$

This term affected the rate of $\mathrm{N}$-specific uptake at each time, $t$, according!y:

$$
V_{t}=V_{N} \times L \text {. }
$$

$V_{t}$ controlled the transfer of nitrogen from the inorganic pool to phytoplankton biomass:

$$
\frac{\mathrm{dN}}{\mathrm{d} t}=V_{t} \times P
$$

where $P$ was the concentration of living particulate nitrogen. The initial concentration of $P$ was $0.01 \mu \mathrm{g}$-atom $\mathrm{N}$ liter $^{-1}-\mathrm{a}$ value consistent with estimates of living biomass in the upwelling source water at Point Conception during OPUS-83 (Wilkerson and Dugdale 1987). Particulate growth and nitrate depletion resulted from the rectangular integration of these coupled equations. A time step of $1 \mathrm{~h}$ was used for all runs.

None of these versions evaluated losses from the particulate nitrogen component caused by sinking, which is probably very low during the early stages of active upwelling (Smith et al. 1983; Bienfang 1985). Grazing, ammonium recycling, and advection from the system were also not included as our intent was to model changes in the ability of the system to grow rapidly on "new" nitrogen (i.e. nitrate).

Alternate hypotheses-Hypothesis 2 as-

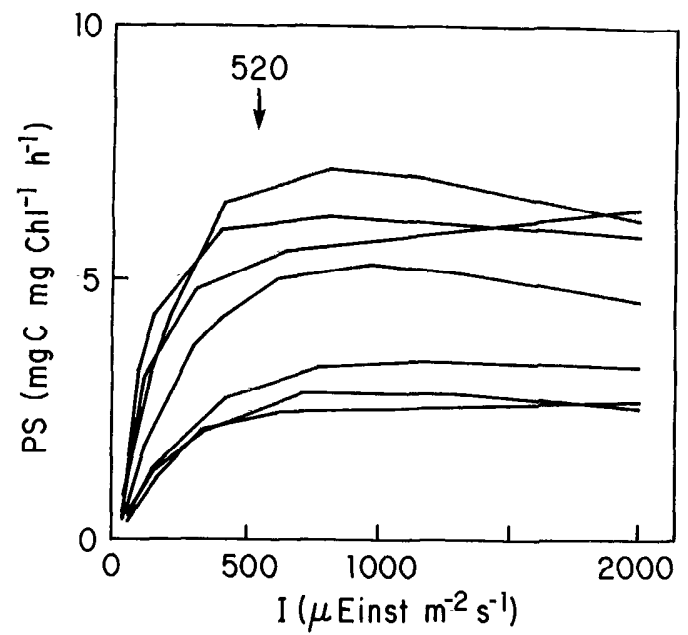

Fig. 3. A composite of photosynthesis-irradiance curves obtained during the OPUS-83 program (SooHoo unpubl.). Photosynthesis appears to saturate at light intensities near $520 \mu$ Einst $\mathrm{m}^{-2} \mathbf{s}^{-1}$.

sumed that the rate of shift-up was constant. Instead of Eq. 2, acceleration of $V_{\max }$ was determined by averaging the data points in Fig. 2, fixing the acceleration rate $(A)$ at $3 \times$ $10^{-4} \mathrm{~h} \cdot 2$.

Hypothesis 3 assumed no acceleration of $V_{\max }$ over time, $A=0$, eliminating Eq. 2 . We attempted to correct for detritus in individual estimates of $V_{\max }$ by assuming balanced growth and a $\mathrm{N}: \mathrm{Chl}$ ratio of 8.3 , based on a $C: N$ of 6 and $C: C h l$ of 50 . Excess $N$ (based on $\mathrm{N}: \mathrm{Chl}$ ) was assumed to be detritus and biomass $\mathrm{N}$ estimates were adjusted accordingly. This resulted in an average $V_{\max }$ of $0.02 \mathrm{~h}^{-1}$ from the pooled data set.

Simulation-To evaluate each hypothesis, we performed 120 runs of the model, each using a different initial nitrate concentration and mixed-layer depth. Results are presented as response surfaces of variables plotted in the plane defined by mixed-layer depth and initial nitrate concentration.

Note especially that in all three hypotheses, physiological parameters related to variation in $V_{\max }$ were calculated directly from field data. Although computed patterns will change with different parameter values, these simulations are mutually consistent as they are based on the same data. 


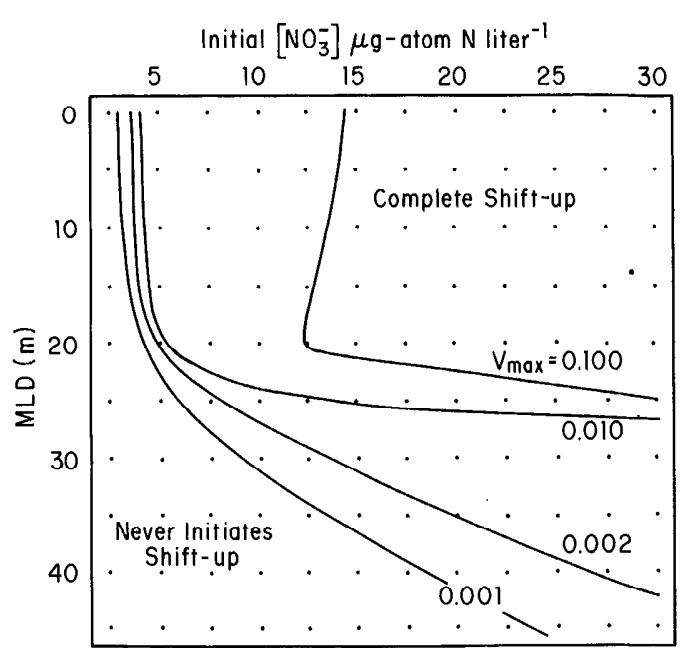

Fig. 4. The peak value of $V_{\max }\left(\mathrm{h}^{-1}\right)$ reached during each run, contoured in the parameter space defined by initial nitrate concentration and mixed-layer depth, as predicted by hypothesis 1 . $V_{\max }$ started out at 0.001 $\mathrm{h}^{-1}$ for all runs and was allowed to increase to a maximum of $0.1 \mathrm{~h}^{-1}$.

This constraint assures a firm basis for comparison without extensive sensitivity analyses as to the value of $A, L$, and $V_{\max }$.

\section{Results}

Hypothesis 1: Shift-up is a function of the initial nitrate concentration-Results of these simulations place definite bounds on conditions favoring major changes in $\mathrm{N}$-specific uptake (Fig. 4). Mixed layers deeper than $25 \mathrm{~m}$ prevented complete shiftup, and the transition between light-limited and nonlight-limited conditions imposed by increasing mixed-layer depth was sharp. For full shift-up, initial nitrate concentrations had to be $>12.5 \mu \mathrm{g}$-atoms $\mathrm{N}$ liter $^{-1}$ and mixed-layer depths had to be $<25 \mathrm{~m}$. Outside these bounds the highest value of $V_{\max }$ attained was a function of both the initial nitrate concentration and the mixed-layer depth. With deep mixed layers and initial nitrate concentrations $>5 \mu \mathrm{g}$-atoms $\mathrm{N}$ liter $^{-1}$, the slanting isopleths indicate that shift-up was controlled by both factors. At intermediate mixed layers and high nitrate concentrations, light limitation prevented complete shift-up. Light limitation was not a factor for mixed layers $<20 \mathrm{~m}$, and nu-

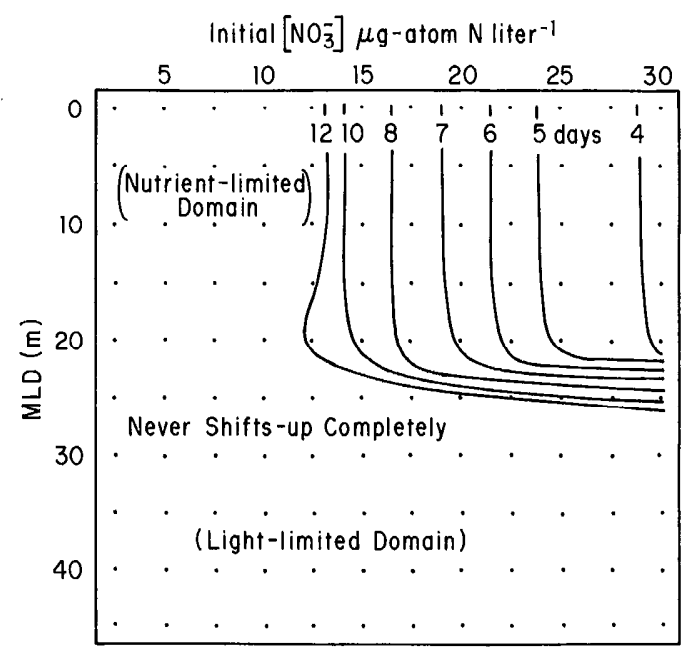

Fig. 5. The time required (d) for $V_{\max }$ to shift-up completely, predicted by hypothesis 1 . Higher initial nitrate concentrations decreased the time required to reach a completely shifted-up state. The model suggests an optimal region where $\mathrm{NO}_{3}^{-}>12.5 \mu$ g-atoms $\mathrm{N}$ liter $^{-1}$ and MLD $<25 \mathrm{~m}$.

trient limitation prevented complete shiftup when initial nitrate concentrations were $<12.5 \mu$ g-atoms $\mathrm{N}$ liter $^{-1}$.

Within the optimal region where full shiftup was possible $\left(\mathrm{NO}_{3}{ }^{-}>12.5 \mu\right.$ g-atoms $\mathrm{N}$ liter ${ }^{-1}$ and $\mathrm{MLD}<25 \mathrm{~m}$ ), the time required to shift-up completely (to the maximum value allowed, $0.1 \mathbf{h}^{-1}$ ) decreased as the initial nitrate concentration increased (Fig. 5). This model predicted that complete shiftup of $V_{\text {max }}$ will occur within 3-12 d, or it will not occur at all. The effect of mixedlayer depth was small above $20 \mathrm{~m}$, but became important below $20 \mathrm{~m}$, as indicated by the steep gradient.

The rate of volume-specific uptake (transport rate or rho, sensu Dugdale) changed both with standing stock and with physiological shifts. Maximum transport rates (corresponding to peak bloom activity) were reached within $8 \mathrm{~d}$ under optimal conditions (Fig. 6A). The greater time required to develop maximum transport rate compared to $V_{\max }$ is due to the role of population size (Eq. 7), which must follow the increase in $V_{t}$. In the region where shift-up was complete (see Fig. 4), bloom activity peaked no later than $12 \mathrm{~d}$ after upwelling. The time 

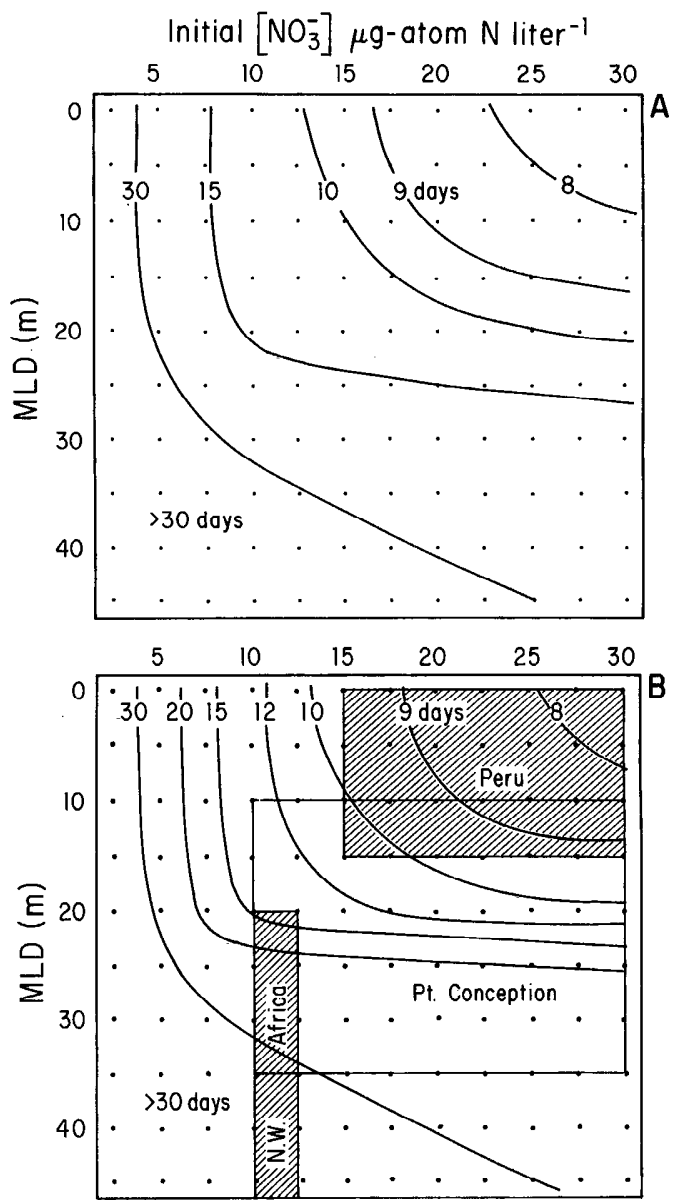

Fig. 6. Time scales of nitrate utilization in hypothesis 1. A. The time required (d) for the transport rate (rho) to peak. As in Fig. 4, increascd initial nitratc concentrations shortened the time required to reach peak bloom activity. B. Time required (d) to exhaust the nutrient supply (hypothesis 1). Nutrients were exhausted more quickly as the initial nitrate concentration increased. Boxes represent approximate conditions observed during upwelling events off Peru, Northwest Africa, and Point Conception (Codispoti et al. 1982; Dugdale and Goering 1970; Dugdale 1985; MacIsaac et al. 1985).

required to reach maximum transport rates also decreased as the initial nitrate concentration increased. Outside the optimal region, the time required for the development of peak bloom activity increased dramatically. Under conditions of severe nutrient and light limitation, no shift-up was possible and the time required to reach peak activity due to growth was much longer than $30 \mathrm{~d}$.

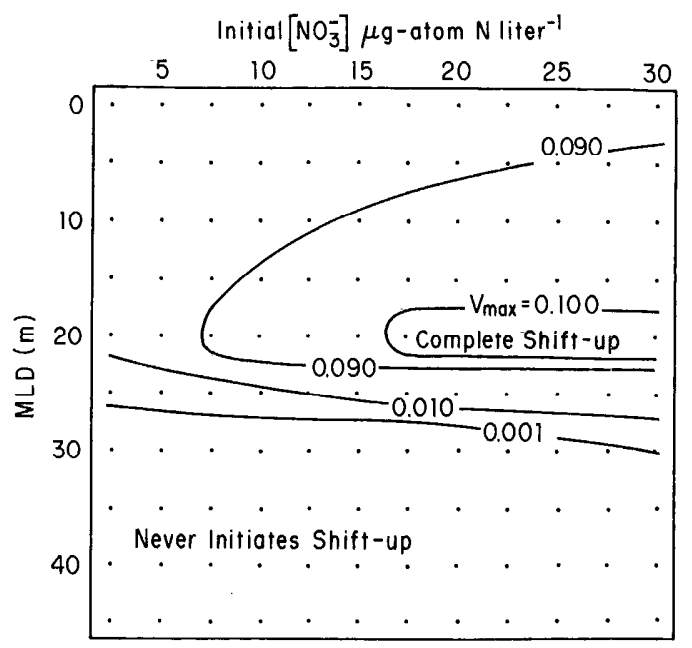

Fig. 7. Peak value of $V_{\max }$ predicted by hypothesis 2. As with hypothesis $1, V_{\max }$ was set to $0.001 \mathrm{~h}^{-1}$ initially and was allowed to increase to a maximum value of $0.1 \mathrm{~h}^{-1}$ (cf. hypothesis 1, Fig. 4).

Although these results follow logically from the assumed dependence of shift-up on ambient nitrate, the temporal pattern of nitrate depletion across the gradient in initial nitrate concentration was somewhat surprising. The time required to exhaust the nutrient pool decreased as the nitrate concentration increased (Fig. 6B). Under conditions of maximum illumination and highest nitrate concentrations, the system became depleted of nitrate in $<8 \mathrm{~d}$. Outside the optimal region, the time required to completely deplete the nitrate pool was $>12$ $\mathrm{d}$, and much of this region required $>30 \mathrm{~d}$ to deplete the nitrate pool. The high growth potential of shifted-up cells in shallow mixed layers resulted in nitrate depletion within 1 $\mathrm{d}$ following the time when bloom activity reached a maximum. Thus panels $A$ and $B$ of Fig. 6 are similar.

Hypothesis 2: Acceleration of nutrient uptake is independent of the initial nitrate concentration - In these runs, the rate of shiftup was held constant at $3 \times 10^{-4} \mathrm{~h}^{-2}$, which was the average acceleration rate observed in the field (Wilkerson and Dugdale 1987). Making shift-up independent of the initial nitrate concentration resulted in both qualitative and quantitative differences in the response surfaces relative to hypothesis 1 . The optimal region of complete shift-up was 

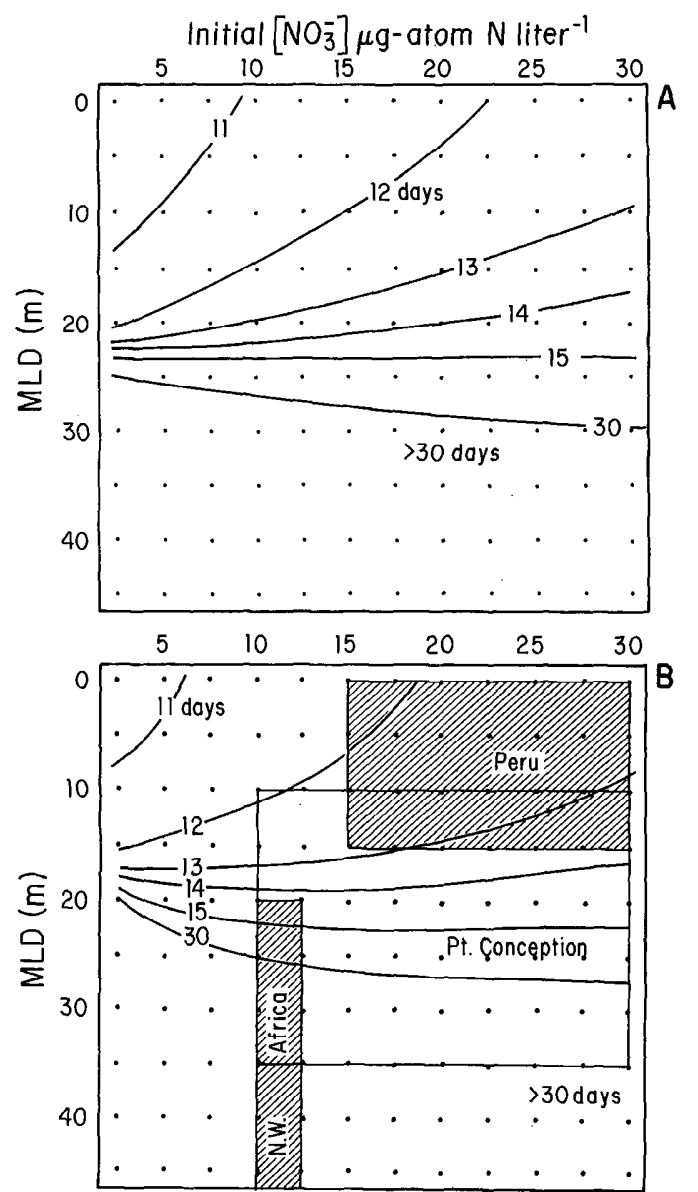

Fig. 8. Time scales of nitrate utilization in hypothesis 2 . A. Time required (d) to reach maximum transport rates predicted by hypothesis 2 . Higher nutrient concentration required more time to reach peak bloom activity (cf. hypothesis 1, Fig. 6A). B. Time (d) required to deplete the nutrient supply predicted by hypothesis 2 (cf. hypothesis 1, Fig. 6B). Boxes as in Fig. 6B.

very small, being bounded by mixed-layer depths between 15 and $25 \mathrm{~m}$ and initial nitrate concentrations $>15 \mu$ g-atoms $\mathrm{N}$ li$\operatorname{ter}^{-1}$ (Fig. 7). Nitrate was depleted before complete shift-up in shallow mixed layers, while light limitation prevented shift-up in deep mixed layers. The decreased importance of initial nitrate concentration throughout parameter space was indicated by the generally flat isopleths of $V_{\max }$ across the nitrate gradient.

A constant rate of shift-up reversed the temporal pattern of nutrient utilization predicted by hypothesis 1 (Fig. 8). Increased

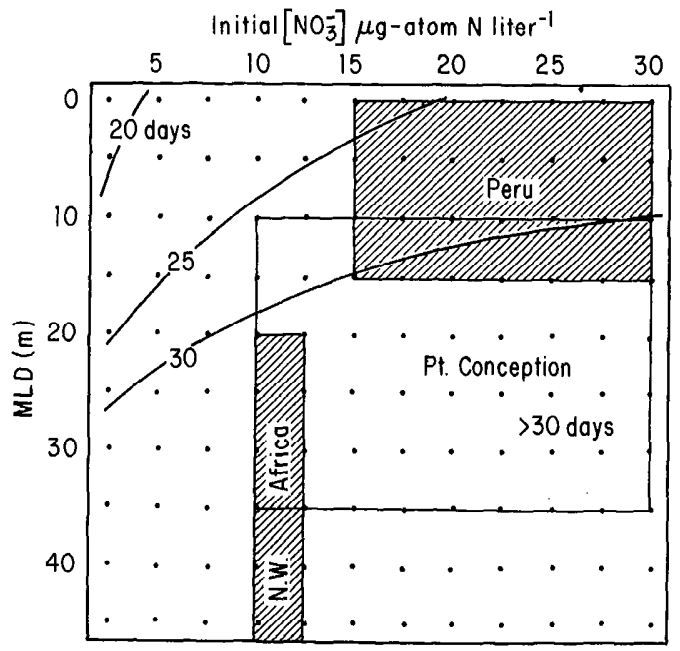

Fig. 9. Time (d) required to deplete the nutrient supply predicted by hypothesis 3 (cf. Figs. $6 \mathrm{~B}$ and $8 \mathrm{~B}$ ). Boxes as in Figs. 6B and 8B.

initial nitrate concentrations delayed the time of maximum transport rates in mixed layers $<25 \mathrm{~m}$ (Fig. 8A). The timing of $\max -$ imum bloom activity depended on both nitrate concentration and mixed-layer depth when initial nitrate concentrations were extremely low and mixed layers were very shallow. Increasing the initial nitrate concentration made the system more dependent on mixed-layer depth, as indicated by the flattened isopleths of time across the nitrate gradient. Light limitation was so severe in mixed layers $>25 \mathrm{~m}$ deep that the time to maximum bloom activity exceeded $30 \mathrm{~d}$.

Nutrient depletion occurred within $24 \mathrm{~h}$ after transport rates peaked in runs with shallow mixed layers (Fig. 8B). In contrast to hypothesis 1 , this version predicted that it will take longer to exhaust the nutrient supply as initial nitrate concentrations increase.

Hypothesis 3: Shift-up is a measurement artifact; maximum velocities of specific uptake do not change in the upwelling systemHypothesizing no shift-up made only a small qualitative change in the pattern of nutrient utilization, as compared to hypothesis 2 . However, it more than doubled the time scale (Fig. 9). Even under conditions of shallow mixed layers and high initial nitrate concentrations, transport rates were maxi- 
Table 1. Results of drifter track experiments performed in the Peru upwelling system at $15^{\circ} \mathrm{S}$ during 1965 and 1977. Nitrate concentrations are expressed as $\mu$ g-atoms $\mathrm{N}$ liter $^{-1}$.

\begin{tabular}{lcccc}
\hline \hline $\begin{array}{c}\text { Drogue } \\
\text { No. }\end{array}$ & $\begin{array}{c}\text { Initial } \\
{\left[\mathrm{NO}_{3}{ }^{-}\right]}\end{array}$ & $\begin{array}{c}\operatorname{Max} V_{t} \\
\left(\mathrm{~h}^{-1}\right)\end{array}$ & $\begin{array}{c}\text { Time to } \\
\max V_{t} \\
(\mathrm{~d})\end{array}$ & $\begin{array}{c}\text { Time to } \\
\mathrm{N} \text { depletion } \\
\text { (d) }\end{array}$ \\
\hline AB15* & 20 & 0.055 & $1-2$ & 4 \\
I-2† & 25 & 0.07 & 6 & $>6$ \\
III-2 $\dagger$ & 23 & 0.09 & 4 & $>2$ \\
III-3† & 24 & 0.11 & 2 & $>2$ \\
\hline
\end{tabular}

* From Dugdale and Gocring 1970

† From MacIsaac et al. 1985.

mum between 25 and $30 \mathrm{~d}$ after upwelling. Higher initial concentrations of nitrate prolonged the time required to deplete the nutrient supply, as in hypothesis 2 .

\section{Discussion}

Simulations based on hypothesis 1 predicted that events leading to bloom formation and maximum algal activity will occur over shorter time scales as the initial nutrient concentration increases. Although this inverse relation may appear counterintuitive at first, it is the result of making the rate of shift-up dependent on nitrate concentration. The qualitative pattern with respect to the timing of nutrient utilization appears more "conventional" under the assumptions of hypothesis 2 , where shift-up of uptake capacity is independent of the initial nitrate concentration, and under hypothesis 3, where shift-up does not occur. However, hypothesis 3 appears to be untenable because it predicted time scales for peak bloom formation to be on the order of 20-30 d after upwelling. Clearly, this is too long, as the critical time scales seem to be on the order of 7-15 d (Walsh et al. 1977; Wroblewski 1977; Barber and Smith 1981; Codispoti et al. 1982). The only way to shorten the time scale under hypothesis 3 would be to increase the mean $V_{\max }$ to a value outside the boundary set by experimental data. The rejection of this hypothesis is important because high levels of nonliving particulate nitrogen were present in samples from the upwelling center at Point Conception (SooHoo 1985). However, these results indicate that simple changes in the ratio of living to detrital nitrogen are in- adequate to explain the observed acceleration in rates of nutrient uptake.

At this point, the data cannot be interpreted to eliminate either hypothesis 1 or 2 absolutely. Both hypotheses predicted similar and reasonable dynamics of shift-up and time-courses of nutrient utilization when compared to field observations in the upwelling systems of Northwest Africa and Point Conception (boxed areas in Figs. 6B and 8B; Codispoti et al. 1982; Dugdale 1985). However, results of four drogue-following experiments performed in the Peru upwelling system are most compatible with hypothesis 1 (cf. Fig. 5 with Table 1). Since mixed-layer depths tend to be shallow $(\leq 20$ $\mathrm{m})$ and nutrient levels high ( $>20 \mu$ g-atoms $\mathrm{N}$ liter ${ }^{-1}$ ), Peru lies in the complete shiftup area of Fig. 4. Although the values of maximum $V_{\iota}$ achieved in each of the drogue experiments are consistent with both hypotheses 1 and $2\left(0.05-0.11 \mathrm{~h}^{-1}\right.$; cf. Figs. 4 and 7), the time required to deplete the system of nutrients $(2-6 \mathrm{~d})$ is most consistent with hypothesis 1 (cf. Figs. 6B and 8B). Analogous experiments covering sufficiently long time scales have not been performed in the Northwest Africa and Point Conception upwelling systems.

Rejection of hypothesis 3 increases our confidence in the phenomenon of shift-up, but the exact mechanism by which natural phytoplankton populations shift-up is unknown. Laboratory studies by Collos (1980, $1982 a, b, 1984)$ provide strong support for a physiological basis for this phenomenon. However, at least part of the shift-up observed in nature may be due to changes in the relative abundance of species with time as was demonstrated using mixed-species cultures in the laboratory (Turpin and Harrison 1979,1980$)$. Preliminary data on species abundance collected from large barrel experiments during OPUS- 83 indicate that changes in relative abundance of species probably do occur, although low phytoplankton abundances in the upwelling source water may make a definitive statement from the OPUS- 83 cell counts difficult. In our model and in interpretations made by Wilkerson and Dugdale (1987), shift-up is viewed conceptually as a changing physiological parameter. However, nothing in this 
model requires that the shift in $V_{\max }$ occur within the cell, only that the biomass-specific rate of nutrient uptake by the phytoplankton population as a whole increases downstream from the point of upwelling.

Although consistent with field observations, hypothesis 1 , with acceleration of $V_{\max }$ depending on the initial nitrate concentration, is an empirical simplification. At whatever level shift-up occurs, it seems more likely to be controlled by changing ambient conditions, perhaps as a moving average of the nutrient history seen by the cells. Available data are insufficient to support this more complex formulation mathematically. Further, this important detail may be difficult to demonstrate in field observations because results from a simulation where shiftup depended on ambient nitrate at each time step were virtually identical to hypothesis 1 .

This analysis has quantified the time scales of nutrient utilization which are consistent with empirical field observations. Taken together, these results and observations provide quantitative evidence for environmental control of transient nutrient-uptake dynamics in the strong gradients of light and nutrients found in upwelling systems.

\section{References}

BArber, R. T., AND R. L. SMITh. 1981. Coastal upwclling ecosystems, p. 31-68. In A. Longhurst [ed.], Analysis of marine ecosystems. Academic.

Bienfang, P. K. 1985. Sedimentation of suspended microparticulate material in the Point Conception upwelling ecosystem. A technical report of research performed during the 1983 OPUS II fieldwork. The Oceanic Inst., Waimanalo, Hawaii. $24 \mathrm{p}$.

Comispoti, L. A., R. C. Dugdale, and J. H. Minas. 1982. A comparison of the nutrient regimes off northwest Africa, Peru and Baja California. J. Cons. Cons. Int. Explor. Mer 180: 184-201.

Collos, Y. 1980. Transient situations in nitrate assimilation by marine diatoms. 1. Changes in uptake parameters during nitrogen starvation. Limnol. Oceanogr. 25: 1075-1081.

- $1982 a$. Transient situations in nitratc assimilation by marine diatoms. 2 . Changes in nitrate and nitrite following a nitrate perturbation. Limnol. Oceanogr. 27: 528-535.

- $1982 b$. Transicnt situations in nitrate assimilation by marine diatoms. 3. Short-term uncoupling of nitrate uptake and reduction. J. Exp. Mar. Biol. Ecol. 62: 285-295.
1984. Transient situations in nitrate assimilation by marine diatoms. 5 . Interspecific variability in biomass and uptake during nitrogen starvation and resupply. Mar. Ecol. Prog. Ser. 17: 2531.

Dugdale, R. C. 1976. Nutrient cycles, p. 141-172. In D. H. Cushing and J. J. Walsh [eds.], The ecology of the sea. Blackwell.

—. 1985. The effects of varying nutrient concentrations on biological productivity in upwelling regions. CalCOFI Rep. 26, p. 93-96.

$\longrightarrow$, AND J. J. GOERING. 1967. Uptake of new and regenerated forms of nitrogen in primary productivity. Limnol. Oceanogr. 12: 196-206.

$\longrightarrow$, AND —. 1970. Nutrient limitation and the path of nitrogen in Peru Current production. Anton Brunn Rep. 5: 5.3-5.8.

MacisaAC, J. J., AND R. C. Dugdale. 1972. Interactions of light and inorganic nitrogen in controlling nitrogen uptake in the sea. Decp-Sea Res. 19: 202-232.

$\longrightarrow,-$ R. T. BARBER, D. Blasco, AND T. T. PACKARD. 1985. Primary production cycle in an upwelling center. Deep-Sea Res. 32: 503-529.

$\longrightarrow, \longrightarrow$, AND G. SlawYK. 1974. Nitrogen uptake in the northwest Africa upwelling area: Results from the Cieneca-Charcott II cruise. Tethys 6: 69-76.

SCCHAECHTER, M. 1968. Growth: cells and populations, p. 136-162. In J. Mandelstam and $\mathrm{K}$. Mcquillen [eds.], Biochemistry of bacterial cell growth. Wiley.

Smith, W. O., G. W. Heburn, R. T. Barber, and J. J. O'BRIEN. 1983. Regulation of phytoplankton communities by physical processes in upwelling ecosystems. J. Mar. Res. 41: 539-556.

SooHoo, J. B. 1985. Carbon uptake at the Pt. Conception upwelling center: The roles of mixing and turbidity in limiting primary production. Eos 66: 1303.

TurPin, D. H., AND P. J. Harrison. 1979. Limiting nutrient patchiness and its role in phytoplankton ecology. J. Exp. Mar. Biol. Ecol. 39: 151-166.

$\longrightarrow$, AND $\longrightarrow$. 1980. Cell size manipulation in natural marine, planktonic, diatom communities. Can. J. Fish. Aquat. Sci. 37: 1193-1195.

Walsh, J. J., J. C. Kelley, R. C. Dugdale, and B. W. Frost. 1977. Gross features of the Peruvian upwelling system with special reference to possible diel variation. Invest. Pesq. 35: 25-42.

Wilkerson, F. P., AND R. C. Dugdale. 1987. The use of large shipboard barrels and drifters to study the effects of coastal upwelling on phytoplankton dynamics. Limnol. Oceanogr. 32: 368-382.

WROBLEWSKI, J. S. 1977. A model of phytoplankton plume formation during variable Oregon upwelling. J. Mar. Res. 35: 357-394.

Submitted: 25 July 1985 Accepted: 19 August 1986 